\title{
Proteasome inhibitor-resistant cells cause EMT-induction via suppression of E-cadherin by miR-200 and ZEB1
}

\author{
TADASHI ASAKURA, NORIKO YAMAGUCHI, KIYOSHI OHKAWA and KIYOTSUGU YOSHIDA \\ Department of Biochemistry, Jikei University School of Medicine, Tokyo 105-8461, Japan
}

Received December 29, 2014; Accepted January 19, 2015

DOI: 10.3892/ijo.2015.2916

\begin{abstract}
Downregulation of E-cadherin (gene: CDH1) plays an important role in epithelial-mesenchymal transition (EMT), which is critical for normal development and disease states. As a result of long-term treatment of endometrial carcinoma Ishikawa cells with epoxomicin (EXM), the cells exhibited the phenotype for EXM-resistance (Ish/EXM cells). Moreover, CDH1 mRNA and its protein were suppressed and EMT was induced in Ish/EXM cells. Ish/EXM cells exhibited drug-resistance to other proteasome inhibitors, MG-132, PSI and PS-341 (Bortezomib). The proteasome inhibitor-resistant cells acquired invasiveness as a result of the chemotherapy. In Ish/EXM cells, E-cadherin was suppressed by upregulation of its transcriptional repressor ZEB1. Furthermore, expression of the miR-200 family (miR-200a, miR-200b, miR-200c and miR-141) found in Ishikawa cells was suppressed in Ish/EXM cells. Overexpression of the miR-200 family in Ish/EXM cells caused by transfection with the pre-miR-200 family induced downregulation of ZEB1 and enhanced expression of E-cadherin. Conversely, suppression of miR-200 expression in the Ishikawa cells by transfection with anti-miR-200 elevated the expression of ZEB1 and suppressed the expression of E-cadherin. These results suggest that acquirement of EXM-resistance in Ish/EXM cells induces up regulation of ZEB1 via suppression of the miR-200 family following suppression of E-cadherin. Since suppression of ZEB1 in Ish/EXM cells by treatment with its siRNA did not restore the miR-200 family expression, miR-200 family was placed upstream of ZEB1 to regulate the expression.
\end{abstract}

\section{Introduction}

The ubiquitin/proteasome system is an extra-lysosomal, ATP-dependent protein degradation system. It participates in

Correspondence to: Professor Tadashi Asakura, Department of Biochemistry, Jikei University School of Medicine, 3-25-8 Nishishinbashi, Minato-ku, Tokyo 105-8461, Japan

E-mail: tad_asakura@jikei.ac.jp

Key words: proteasome inhibitor, drug resistance, epithelialmesenchymal transition, E-cadherin, ZEB1, miR-200 the control of many cellular signals that concern proliferation, growth, differentiation and death, namely apoptosis, of the cells (1-6). It is the $26 \mathrm{~S}$ proteasome that serves as the center of this degradation mechanism and is within the huge enzyme complex, which acts as the center of the functional control of the cells (1-7). The suppression of proteasome activity that participates in many life phenomena leads to death, i.e. apoptosis of the cell. The use of such inhibitors for this multifunctional enzyme complex, 'proteasome' as anticancer drug has been attempted in recent years (8-20). Proteasome inhibitor is a drug with highly anticipated efficacy as an anticancer drug for clinical use. PS-341, an inhibitor, is already applied for a multiple myeloma $(9,10,12,17,21,22)$. However, there are scarce data available on the clinical use of a proteasome inhibitor as an anticancer drug. In addition to noting any systemic side effect, evaluation whether cancer cells acquiring resistance to a proteasome inhibitor reappear after inadequate or incomplete cancer therapy is necessary in this type of agents. To evaluate the possible generation of cells resistant to the inhibitor and their specific properties it is necessary to work out a strategy for the second line chemotherapy. Therefore, a squamous cell carcinoma cell line A431 resistant to epoxomicin (EXM) (23), which is a proteasome-specific inhibitor, was established and some features were examined to overcome the resistance to treatment (24).

Normally, epithelial cells are tightly interconnected through several junctional structures, including tight junctions and adherens-type junctions, which are intimately associated with the actin and intermediate cytoskeleton. The activation of epithelial-mesenchymal transition (EMT) allows cells to dissociate from the epithelial type to mesenchymal type. EMT is a process vital for morphogenesis during embryonic development and has also been implicated in the transition of early-stage tumors into invasive malignancies. This type of conversion results in the loss of cell-cell contacts and a dramatic remodeling of cytoskeleton in the epithelial cell layers $(25,26)$. E-cadherin is a cell-cell adhesion molecule and the loss of its expression is a hallmark of EMT. Reduction of the E-cadherin increased cell mobility and promoted tumor cell invasion (27-29).

The loss of E-cadherin has been shown to be an important event for the invasion of epithelial tumor cells. Several mechanisms have revealed that the loss of E-cadherin expression can occur either genetically or epigenetically during tumor progression $(30,31)$. Hyper-methylation and chromatin 
remodeling of the E-cadherin gene have emerged as the main mechanisms for the downregulation of E-cadherin in most carcinomas. The dysfunction in the regulation of E-cadherin expression plays an essential role in pathological processes such as tumor progression.

We reported previously that stabilization of cell surface E-cadherin during EMT induced by TGF- $\beta$ or during scattering by hepatocyte growth factor can be blocked by inhibiting proteasome with MG132 and lactacystin, and that this inhibition results in transcriptional suppression of E-cadherin mRNA (24). We concluded that the proteasome plays a crucial role in E-cadherin trafficking during EMT (24).

The Snail family transcription factors have been shown to play major roles in E-cadherin repression and these factors have been proposed to act as inducers in the invasion process, including the zinc-finger factors snail (32-34). The two-handed zinc factor family, ZEB1 and ZEB2 (SIP-1), and the basic helix-loop-helix family factors, E12/E47 and Twist, also demonstrated their downregulated effects to repress E-cadherin gene expression (35-37).

MicroRNAs (miRNAs) are small non-coding RNAs, usually 21-23 nucleotides long, which regulate gene expression, primarily at the posttranscriptional level. So far, more that 400 miRNAs have been identified in mammalian cells, with each miRNA having several target genes. The broad spectrum of genes that can be targeted by a single miRNA is attributed to the high level of conservation of the target motifs, known as seed sequences, within the 3 '-untranslated region (UTR) ${ }^{2}$ of the target genes, thus making them the most powerful regulators of gene expression in complex cellular processes, including cancer cell invasion and metastasis (38-45). miRNAs are initially synthesized by polymerase II as long primary transcripts, which are subsequently processed into $\sim 70$-nt stem-loop pre-miRNAs by Drosha RNase III endonuclease (46) and are transported out of the nucleus by exportin 5 (47). Pre-miRNAs are further processed in the cytoplasm by Dicer to yield the final 21-23-nt mature miRNAs (48). Binding of miRNA to target mRNAs with perfect or near perfect complementarity induces mRNA degradation, whereas imperfect complementarity often induces translational repression. It is believed that 7-8 nt in the $5^{\prime}$ end of miRNAs, referred to as the seed sequence, are critical for efficient targeting.

miRNAs have been implicated in regulating complex physiological processes such as embryogenesis (49), organ development (50), and oncogenesis $(40,51)$. However, the functional roles of a vast majority of miRNAs remain unknown. Previously, several groups have used a variety of model systems to identify different miRNAs as promoters or suppressors of metastasis (52-56). Although these studies clearly implicate these miRNAs in metastasis, it is unclear which step(s) in the multistep metastatic progression these miRNAs regulate.

Several miRNAs have been found to function as tumor suppressors, such as miR15a, miR16-1, and let-7 (40,57-61), whereas others were found to possess oncogenic properties, including miR155, miR17-5p and miR21 $(40,62,63)$. Previously, the miR200 family has been found to play a central role in the regulation of EMT process during cancer progression and metastasis (39,41-45,64-68). EMT, while being a critical process during embryonic development and wound healing (69), also plays a fundamental role in cancer metastasis, where cancer cells acquire their invasive phenotype by undergoing a change from the differentiated to a more dedifferentiated state $(38,66,69-72)$.

Applying a classical model system of inducing EMT in several cells, some studies showed that members of the miR-200 family, existing as two clusters in the genome, are significantly repressed during EMT, suggesting a role as suppressors of EMT.

Since the proteasome inhibitor EXM-resistant endometrial carcinoma Ishikawa cells (Ish/EXM cells) prepared by us, suppressed E-cadherin and induced EMT, we studied here the mechanism of E-cadherin suppression in Ish/EXM cells for an association between transcriptional suppression factor and miRNA.

\section{Materials and methods}

Cell lines. Human endometrial carcinoma cell line, Ishikawa, and EXM-resistant Ishikawa cells (Ish/EXM cells) were cultured with RPMI-1640 (Wako Chemicals, Japan) containing $10 \%$ heat inactivated fetal bovine serum (growth medium) under conventional conditions.

Cytotoxicity of proteasome inhibitor and DXR. To assess the growth inhibitory effect of proteasome inhibitors (EXM, MG-132, PSI and PS-341, Peptide Instrument, Japan) and DXR (Kyowa Hakko Kogyo, Japan), viable Ishikawa and Ish/EXM cells $\left(2 \times 10^{4}\right)$ were cultured continuously for $96 \mathrm{~h}$ in a 48 -well culture plate (Greiner Japan) with $0.5 \mathrm{ml}$ of EXM, MG-132, PSI, PS-341 or DXR containing growth medium at graded equivalent concentrations of each drug. After incubation, viable cells were determined with a colorimetric assay using MTS (3-(4,5-dimethylthiazol-2-yl)-5-(3-carboxymethoxyphenyl)2-(4-sulfophenyl)-2H-tetrazolium, inner salt (CellTiter $96^{\circledR}$ Aqueous, Promega) as previously described (34), and the results were expressed by the following equation: viable cells $(\%)=$ $100 \times$ (absorbance at $490 \mathrm{~nm}$ of the treated cells) / (absorbance at $490 \mathrm{~nm}$ of the untreated cells) (35-42).

Assay of proteasome activity. Proteasome activity was measured in $100 \mu \mathrm{M}$ of Suc-Leu-Leu-Val-Tyr-amino-methylcoumarin (Suc-LLVY-AMC, for chymotrypsin-like activity) or Boc-Leu-Arg-Arg-amino-methyl-coumarin (Boc-LRR-AMC, for trypsin-like activity), respectively, monitored for AMC liberation at $37^{\circ} \mathrm{C}$ for $15 \mathrm{~min}$ in a spectrofluorometer at an excitation/emission wavelength of $380 / 460 \mathrm{~nm}$, and expressed as nmol AMC per min per mg protein (35). Reaction mixture contained 0.05 M HEPES-NaOH (pH 7.5), $2 \%$ glycerol, 2 mM dithiothreitol and $100 \mu \mathrm{M}$ substrate. Triton X-100 extracts (1\%) from cells were used as enzymatic source.

Semi-quantitative PCR analysis. Total RNA of Ishikawa and Ish/EXM cells were purified using the RNeasy Plus mini kit (Promega). The cDNA was prepared by reverse transcription (Prime Script reverse transcription kit, Takara) using total RNA, and the expression level of CDH1 (E-cadherin), ZEB1, ZEB2, Snail, Slug, and Twist were measured by PCR (GoTaq Green Master Mix, Promega) using the obtained cDNA as a template; the amplification number for each gene was 26, 28, 35, 45, 35 and 33 cycles, respectively. Each factor was compared 
with $\beta$-actin as an internal standard. The primers used (Fasmac Co. Ltd., Greiner Japan) for each factor were: $\beta$-actin (254 bp): AACACCCCAGCCATGTAC (sense), ATGTCACGCA CGATTTCC (antisense), CDH1 (567 bp): GGTTCAAGC TGCTGACCTTC (sense), AGCCAGTTGGCAGTGTCTCT (antisense), COL1A2 (486 bp): TGCTCAGCTTTGTGGAT ACG (sense), CCTGTGGTCCAACAACTCCT (antisense), CNX26 (421 bp): CTACTTCCCCATCTCCCACA (sense), GACATTCAGCAGGATGCAAA (antisense), CTNNB1 (394 bp): CCCACTAATGTCCAGCGTTT (sense), AATCC ACTGGTGAACCAAGC (antisense), VIN (170 bp): GAG AACTTTGCCGTTGAAGC (sense), TCCAGCAGCTTCC TGTAGGT (antisense), CDH2 (527 bp): GGACAGTTCCTG AGGGATCA (sense), TGGTTTGACCACGGTGACTA (antisense), FN1 (196 bp): TGTTCGTGCAGCTGTTTACC (sense), GCCACCGTAAGTCTGGGTTA (antisense), ZEB1 (537 bp): GCACCTGAAGAGGACCAGAG (sense), TGGTGATGC TGAAAGAGACG (antisense), ZEB2 (393 bp): TTCCTGGG CTACGACCATAC (sense), TTTACCTTCCAGCAGCCCTA (antisense), Snail (415 bp): TTTACCTTCCAGCAGCCCTA (sense), CCAGGCTGAGGTATTCCTTG (antisense), Slug (415 bp): CTTTTTCTTGCCCTCACTGC (sense), ACAGCA GCCAGATTCCTCAT (antisense), Twist (468 bp): CTGAGC AACAGCGAGGAAG (sense), CATCTTGGAGTCCAG CTCGT (antisense), and E47/E12 (567 bp): GCACTGGCCT CGATCTACTC (sense), GGCCTTCAGCTCCTTCTTCT (antisense).

Transwell invasion assay. For the invasion assay, $1 \times 10^{5}$ cells were plated in the top chamber onto a Matrigel-coated membrane (24-well insert; pore size, $8 \mu \mathrm{m}$, Greiner Japan). Each well was coated freshly with Matrigel $(60 \mathrm{mg})$ before the invasion assay. Cells were plated in medium without serum or growth factors, and medium supplemented with serum was used in the lower chamber. The cells were incubated for $24 \mathrm{~h}$ and cells that did not invade through the pores were removed by a cotton swab. Cells on the lower surface of the membrane were fixed with methanol and stained with crystal violet. The number of cells invading through the membrane was counted under a light microscope (three random fields per well).

Promoter methylation assay. Genome DNA from both Ishikawa and Ish/EXM cells was purified using the QIAamp DNA Mini kit (Qiagen). Methylation of the promoter $\mathrm{CpG}$ island in the CDH1 gene was detected using the MethylEasy Xceed: Rapid DNA Bisulphite Modification kit (Human Genetic Signatures). Treatment with bisulphate converts cytosines to uracils whereas 5-methylcytosines remain unreactive. Methylation of the E-cadherin promoter was determined by PCR using bisulphate-treated DNA as a template. Primers used for unmethylation and methylation of the promoter $\mathrm{CpG}$ island in the CDH1 gene were as follows: unmethylation, TAATTTTAGGTTAGAGGGTTATTGT (sense) and AACTC ACAAATCTTTACAATTCCAACA (antisense); methylation, TTAGGTTAGAGGGTTATCGCGT (sense) and CTCACAA ATACTTTACAATTCCGACG (antisense).

Detection of miRNA. miRNA was analyzed using the QuantiMir kit (System Bioscience: SBI, USA). Briefly, total RNA purified by the above described method including the small RNA fraction, was used as starting material. miRNA was tailed with polyA, annealed with oligo-dT adaptor, and then first strand cDNA was created by reverse transcription. The expression level of miRNA was measured by PCR using the obtained cDNA as a template, and the primers used were as follows: forward, miRNA-specific sequence; reverse, universal reverse primer into the oligo-dT adaptor sequence.

Knockdown of transcriptional suppression factor in Ish/EXM cells. SiRNA for human ZEB1, ZEB2, Snail, Slug or Twist (150 pmol in $10-\mathrm{cm}$ dish) was transfected into Ish/EXM cells using the siPORT NeoFX transfection reagent (Life Technologies).

Regulation of miR-200 family expression in Ishikawa and Ish/EXM cells. Pre- and anti-miRNA for the miR-200 family (chemically modified double-stranded RNAs that mimic the endogenous miR-200 family, Life Technologies) (150 pmol in a $10-\mathrm{cm}$ dish) were transiently transfected into Ish/EXM and Ishikawa cells, respectively, using Lipofectamine RNAiMax. Pre-miR Negative Control (a random sequence miRNA mimic molecule that has been extensively tested in human cell lines and tissues and validated to not produce identifiable effects on known miRNA function) was transfected using Lipofectamine RNAiMax. Following transfection, cells were starved overnight and then the total RNA was extracted as described previously. Using RT-PCR, expression of the miR-200 family, E-cadherin and ZEB1 was measured as described above.

Western blot analysis. E-cadherin and ZEB1 in the cell extract with $1 \%$ Triton X-100 were separated by SDS-PAGE (5-20\% gradient acrylamide) and analyzed by western blotting using anti-E-cadherin antibody (Cosmo Bio Co.) and anti-ZEB1 antibody (Sigma-Aldrich Japan) as the primary antibody and alkaline phosphatase-labeled anti-rabbit IgG as the secondary antibody (Sigma-Aldrich, Japan).

Protein determination. Protein concentration was assayed by a Bio-Rad protein assay kit using bovine serum albumin as the standard.

\section{Results}

Establishment of EXM-resistant variants. EXM-resistant variants of Ishikawa cells were obtained by exposure to EXM. Initial induction of resistance was achieved by continuous exposure of Ishikawa cells to EXM $(6.25 \mathrm{nM})$ over 2 months. Growing resistant cells were further treated with gradually increasing concentrations of EXM (increasing every 4 weeks) until the concentration finally reached $60 \mathrm{nM}$ of EXM. The resistant Ishikawa cells that survived exposure to $60 \mathrm{nM}$ EXM were designated as Ish/EXM cells. Ish/EXM cells were cloned by the limiting dilution method in a 96-well culture plate. Acquirement of EXM-resistance in Ishikawa cells is shown in Fig. 1A.

Acquirement of EXM-resistance in Ishikawa cells and proteasome activity. Cytotoxic effect of EXM on Ishikawa and Ish/EXM cells was measured using the MTS method. The $50 \%$ growth inhibition concentration $\left(\mathrm{IC}_{50}\right)$ for EXM against 

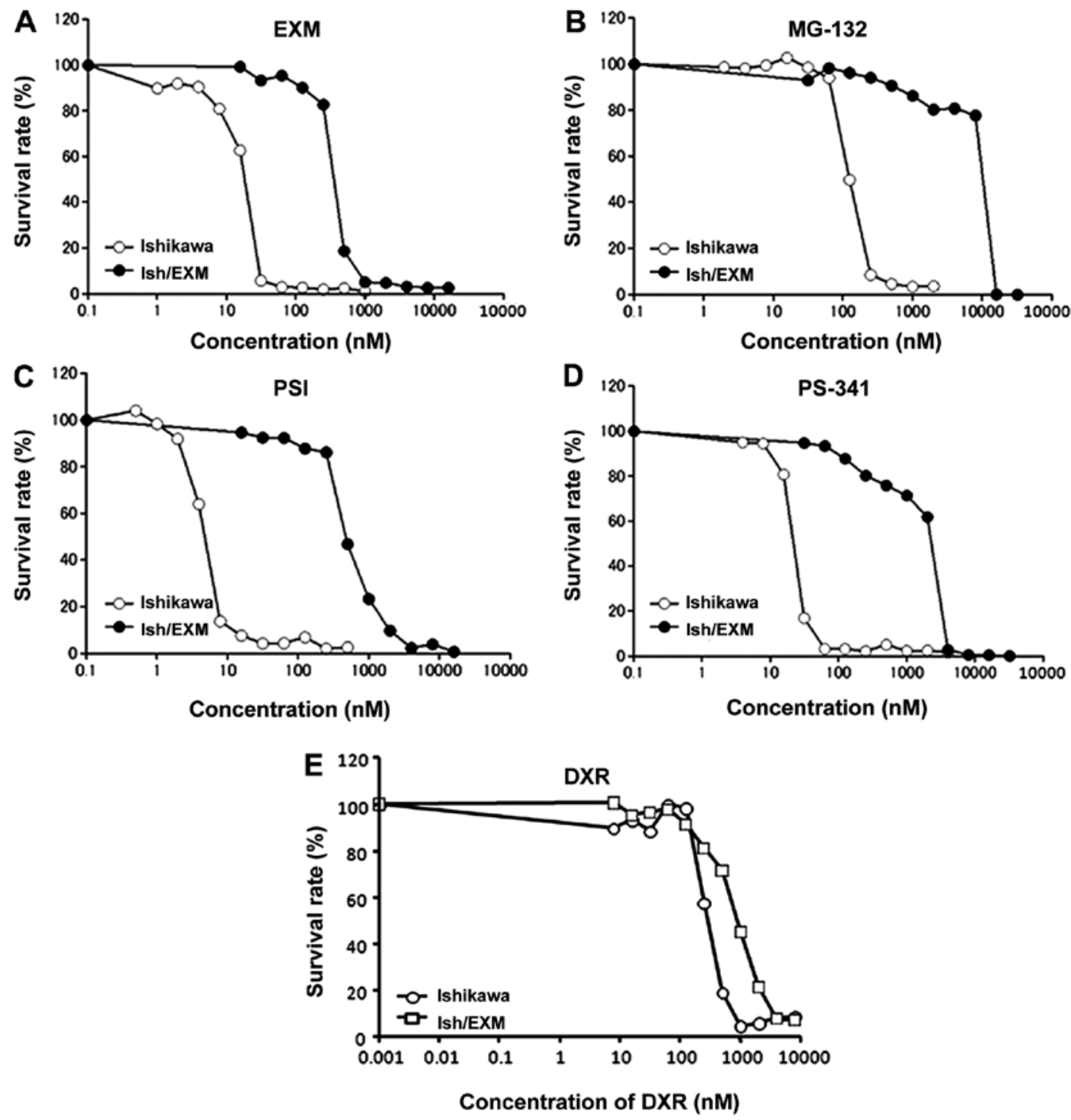

Figure 1. Cytotoxicity of EXM (A), MG132 (B), PSI (C), PS-341 (D) and DXR (E) against Ishikawa and Ish/EXM cells. The cells were cultured continuously for $96 \mathrm{~h}$ at $37^{\circ} \mathrm{C}$ in a 48 -well culture plate with $0.5 \mathrm{ml}$ of EXM, MG-132, PSI, PS-341 or DXR containing growth medium at graded equivalent concentrations of each drug. After incubation, MTS reagent was added to each well and measured at $490 \mathrm{~nm}$.

Ishikawa and Ish/EXM cells was $20 \pm 1.7$ and $400 \pm 28 \mathrm{nM}$, respectively (Fig. 1A, 3 independent experiments). Cytotoxicity of the other proteasome inhibitors, MG132, PSI and PS-341 against these cells was assayed. Ish/EXM cells were also acquired for these inhibitors, and the $\mathrm{IC}_{50}$ values of Ishikawa and Ish/EXM cells were: $125 \pm 11$ and $1200 \pm 105 \mathrm{nM}$ for MG132, $4 \pm 0.32$ and $500 \pm 35 \mathrm{nM}$ for PSI, and $20 \pm 1.2$ and $3000 \pm 250 \mathrm{nM}$ for PS-341, respectively (Fig. 1B, C and D), 3 independent experiments). However, sensitivity to DXR against Ish/EXM cells showed 3-fold resistance compared to that against Ishikawa cells (Fig. 1D). Proteasomal activity in Ishikawa and Ish/EXM cells was $7.2 \pm 0.8$ and $1.0 \pm 0.2 \mathrm{nmol} / \mathrm{min} / \mathrm{mg}$ protein for chymotrypsin-like activity, and $6.9 \pm 0.8$ and $4.7 \pm 0.6 \mathrm{nmol} /$ $\mathrm{min} / \mathrm{mg}$ protein for trypsin-like activity, respectively ( 3 independent experiments).

Suppression of E-cadherin and expression of transcriptional suppression factor in Ish/EXM cells/Induction of EMT in Ish/EXM cells. Acquirement of EXM-resistance led to the disappearance of both E-cadherin mRNA (CDH1) and its protein in Ish/EXM cells (Fig. 2) and induction of EMT in Ish/EXM cells. Moreover, suppression of the epithelial markers COL1A2, CNX26 and CTNNB1, and overexpression of the mesenchymal markers VIN, CDH2 and FN1 were observed in Ish/EXM cells relative to Ishikawa cells. Since E-cadherin expression is known to be regulated by a transcriptional suppression factor, we used RT-PCR to measure mRNA expression of several factors related to E-cadherin suppression, specifically Snail, Slug,ZEB1,ZEB2, E12/E47 and Twist, in Ish/EXM cells. Among these suppressors concerning EMT-induction, expression of ZEB1 and ZEB2 was especially enhanced in Ish/EXM cells, and expression of the ZEB1 protein was markedly increased (Fig. 2A). Expression of Slug, Snail and Twist mRNA was also substantially increased in the cells. However, no change in E12/E47 mRNA was observed in Ishikawa or Ish/EXM cells.

Methylation profile of E-cadherin promoter in Ishikawa and Ish/EXM cells. Since promoter hyper-methylation is known to result in transcriptional downregulation of the E-cadherin gene, we measured methylation of the E-cadherin promoter. 
A

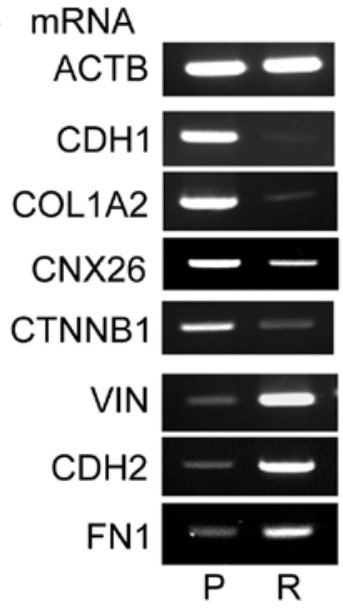

B Protein

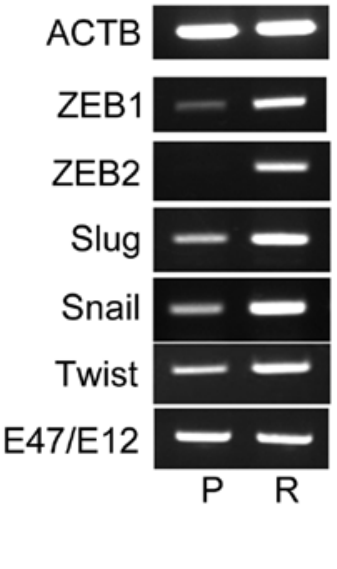

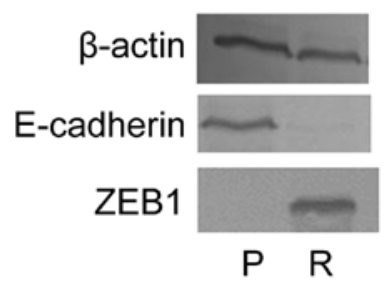

C Methylation of $\mathrm{CDH} 1$ promoter region

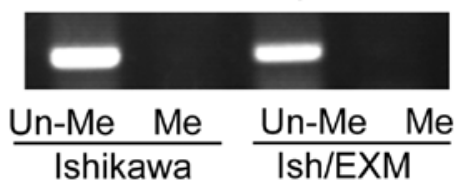

Figure 2. Expression of mRNA level of epithelial marker (CDH1, COL1A2, CNX26, CNTB1), mesenchymal marker (VIN, CDH2, FN1), and transcriptional repressors (ZEB1, ZEB2, Slug, Snail, Twist, E47/E12) by acquirement of EXM-resistance (A), and of the protein level of E-cadherin and ZEB1 (B). P, Ishikawa cells, R, Ish/EXM cells. The methylation profile of this E-cadherin promoter fragment in CpG islands of both Ishikawa and Ish/EXM cells (C). Un-Me, unmethylation in $\mathrm{CpG}$ islands; $\mathrm{Me}$, methylation in $\mathrm{CpG}$ islands.

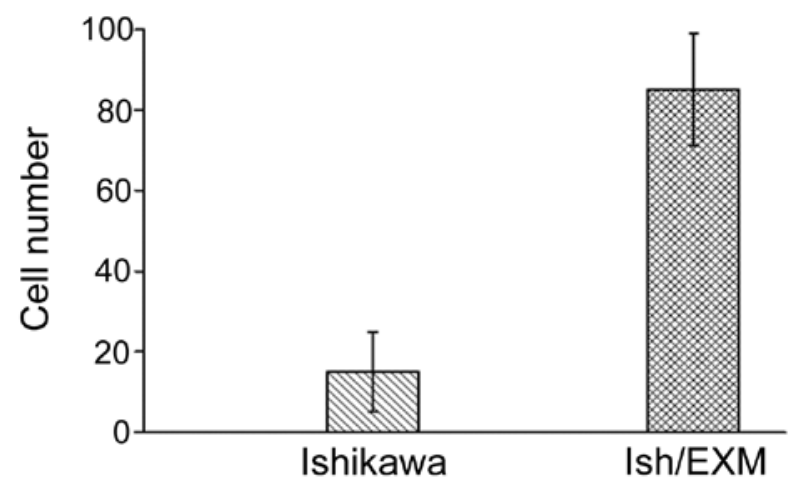

Figure 3. Increase in invasive capacity by acquirement of EXM-resistance. The number of invading cells in Ishikawa and Ish/EXM cells. Data represent mean \pm SD. $\mathrm{P}<0.001$ : significantly different from control.

The methylation profile of this E-cadherin promoter fragment contained unmethylated $\mathrm{CpG}$ islands in both Ishikawa and Ish/EXM cells (Fig. 2C).

Increase in invasive capacity of Ish/EXM cells. Since E-cadherin was suppressed in Ish/EXM cells, it was expected that EMT would be induced in these cells. Therefore, we measured migration of both Ishikawa and Ish/EXM cells. Invasive capacity of Ish/EXM cells increased 5.7-fold compared with that of Ishikawa cells (Fig. 3, 3 independent experiments).

E-cadherin expression by suppression of transcriptional repression factor in Ish/EXM cells. For identification of the primary transcriptional suppressor for E-cadherin suppression, each factor of Snail, Slug, ZEB1, ZEB2 and Twist, was knocked down in Ish/EXM cells. Treatment of Ish/EXM cells with ZEB1 siRNA but not with ZEB2, Snail, Slug or Twist siRNA restored the expression of both E-cadherin mRNA and its protein (Fig. 4). Of note, treatment of Ish/EXM cells with ZEB2 siRNA partially restored expression of E-cadherin mRNA (Fig. 4).
siZEB1-treatment (left: mRNA, right: protein)
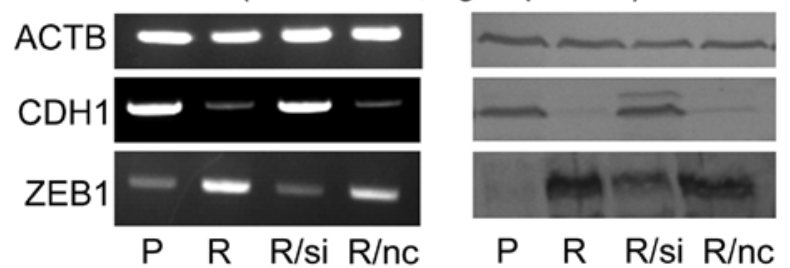

siZEB2-treatment (mRNA)

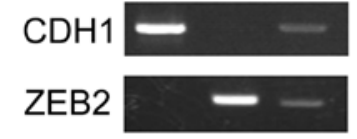

siSlug-treatment (mRNA)

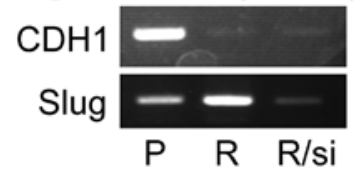

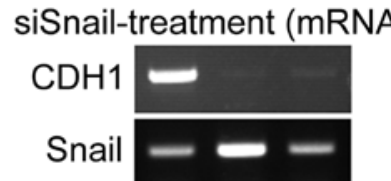

siTwist-treatment (mRNA)

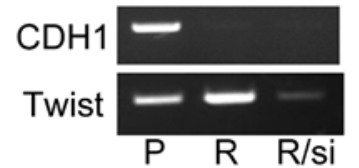

Figure 4. Effect of the knock-down of transcriptional repressors (ZEB1, ZEB2, Snail, Slug and Twist) by transfection with their respective siRNA on E-cadherin expression. R/si, R/nc; treatment of Ish/EXM cells (R) with siRNA for each transcriptional repressor and non-coding RNA, respectively. P, Ishikawa cells.

Cytotoxic effect of EXM on CDH1-suppressed Ishikawa cells and ZEB1-repressed Ish/EXM cells. We studied whether the sensitivity of EXM decreased with CDH1-supressed Ishikawa cells by transfection of siRNA for CDH1. Conversely, we studied whether the sensitivity of EXM rose with Ish/EXM cells by transfection of siRNA for ZEB1. Acquirement of EXM-resistance led to the disappearance of both E-cadherin mRNA (CDH1) and its protein in Ish/EXM cells (Fig. 2) and induction of EMT in Ish/EXM cells.

Since the $\mathrm{IC}_{50}$ value for EXM against CDH1-supressed

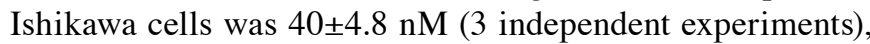
sensitivity to EXM against CDH1-supressed Ishikawa cells showed 2-fold resistance compared to that against Ishikawa 


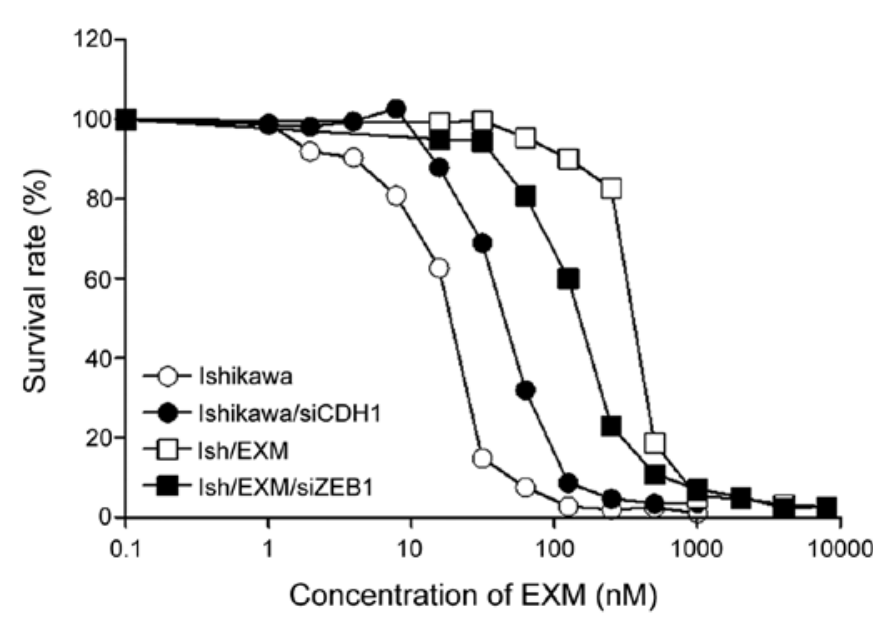

Figure 5. Cytotoxic effect of EXM on CDH1-suppressed Ishikawa cells and ZEB1-repressed Ish/EXM cells. Ishikawa and Ish/EXM cells were cultured for 2 days after transfection with siRNA for CDH1 and ZEB1, respectively, and then these cells were cultured continuously for $96 \mathrm{~h}$ at $37^{\circ} \mathrm{C}$ in a 48 -well culture plate with $0.5 \mathrm{ml}$ of EXM containing growth medium at graded equivalent concentrations of EXM. After incubation, MTS reagent was added to each well and measured at $490 \mathrm{~nm}$. Control cells were transfected with non-coding siRNA.

cells (Fig. 5). Since the $\mathrm{IC}_{50}$ value for EXM against the ZEB1supressed Ish/EXM cells was $300 \pm 45 \mathrm{nM}$ (3 independent experiments), sensitivity to EXM against ZEB1-supressed Ish/ EXM cells showed 1.3-fold higher susceptibility compared to that against Ish/EXM cells (Fig. 5).

Suppression of miRNA controlling EMT in Ish/EXM cells. Since several miRNAs have been found to regulate EMT, such as miR-9, miR-10a, miR-10b, miR-21, miR-23a, miR-23b, miR-27a, miR-27b, miR-34a, miR-141, miR-150, miR-192, miR-200a, miR-200b, miR-200c, miR-205, miR-206, miR-215, miR-217, miR-221, miR-298, miR-374b, miR-382, miR-429, miR-508-3p, and miR-539, we measured the expression of these miRNAs in Ishikawa and Ish/EXM cells. Shown in Fig. 6, miR-200a, miR-200b, miR-200c and miR-141 (miR-200 family) were suppressed in Ish/EXM cells. Therefore, the miR-200 family was regarded as a candidate for inducing EMT in Ish/EXM cells.

Regulation of ZEBI expression by the miR-200 family. Since the miR-200 family was suppressed in Ish/EXM cells, we measured the expression of these miRNAs in Ishikawa and Ish/EXM cells, and investigated the effect of transfection with anti- or pre-miR-200 family (miR-200a, miR-200b, miR-200c and miR-141) on both transcriptional suppression factor and E-cadherin expression in Ishikawa or Ish/ EXM cells, respectively. Expression of the miR-200 family in Ish/EXM cells by transfection with the pre-miR-200 family led to suppression of ZEB1. Moreover, expression of E-cadherin was observed in Ish/EXM cells transfected with the pre-miR-200 family (Fig. 7). By contrast, suppression of the miR-200 family in Ishikawa cells by transfection with the anti-miR-200 family led to both expression of ZEB1 and suppression of E-cadherin (Fig. 7). On the other hand, since suppression of ZEB1 in Ish/EXM cells caused by treatment with its siRNA did not restore miR200 family expression, the

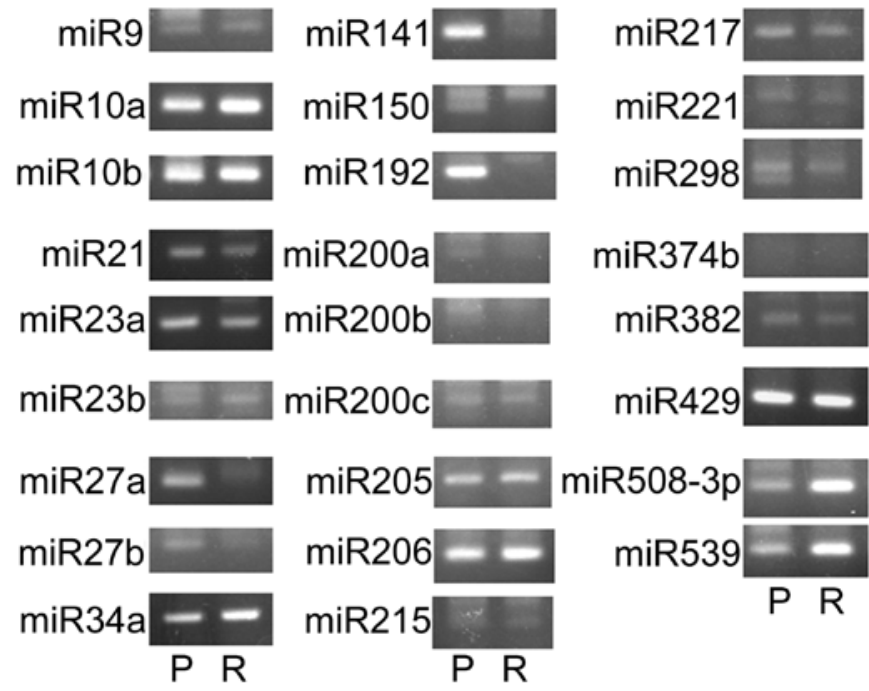

Figure 6. Comparison of the expression of several miRNAs in Ishikawa $(\mathrm{P})$ and Ish/EXM cells (R). MiRNA was tailed with polyA, annealed with oligo$\mathrm{dT}$ adaptor, and then first strand cDNA was created by reverse transcription using the QuantiMir kit. The expression level of miRNA was measured by PCR using the obtained cDNA as a template, and the primers used were: forward, miRNA-specific sequence; reverse, universal reverse primer into the oligo-dT adaptor sequence.

miR200 family was placed upstream of ZEB1 to regulate the expression (Fig. 8).

\section{Discussion}

Proteasome inhibitor is a drug with highly anticipated efficacy as an anticancer agent for clinical use. The inhibitor, PS-341 (Bortezomib), is already in use for multiple myeloma $(9,10,12,17,21,22)$. However, there are scarce data available on the clinical use of a proteasome inhibitor as an anticancer drug. Very careful use of this type of agent is necessary, noting any systemic side effect, and whether cancer cells acquiring resistance to a proteasome inhibitor reappear after inadequate or incomplete cancer therapy. When Ishikawa cells acquired resistance to the proteasome inhibitor epoxomicin (EXM), the cells caused EMT and suppressed E-cadherin. Induction of EMT was confirmed by suppression of the epithelial markers CDH1, COL1A2, CNX26 and CTNNB1, and overexpression of the mesenchymal markers VIN, CDH2, FN1, ZEB1 and ZEB2 in Ish/EXM cells.

The proteasome inhibitor-resistant cells acquired invasiveness through chemotherapy and the cells became even more malignant. EXM-resistant Ish/EXM cells acquired crossresistance for MG-132, PSI and PS-341, and other proteasome inhibitors (Fig. 1A-D). However, Ish/EXM cells showed a 3-fold resistance to DXR compared to Ishikawa cells (Fig. 1E). In generation, DXR-resistant cells exhibited Pgp (MDR mechanism) expression and DXR was released from the cells using the ATP-dependent transporter, Pgp. In EXM-resistant cells, it was suggested that detoxification activity for proteasome inhibitors was enhanced, because enhanced expression of the Cytochrome P450 family and ALDH as a detoxification enzyme was observed in Ish/EXM cells (data not shown).

Expression of ZEB1 among the transcriptional suppression factors caused suppression of E-cadherin in Ish/EXM cells. 
A mRNA expression

(I) $\mathrm{miR} 200 \mathrm{a}$

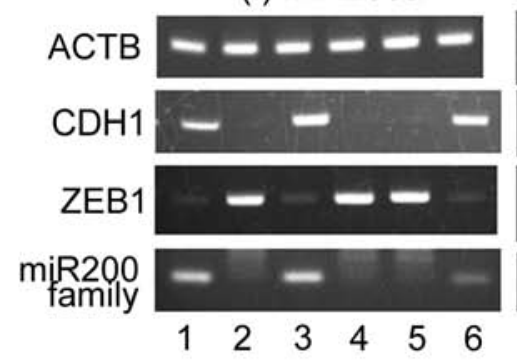

(II) miR200b

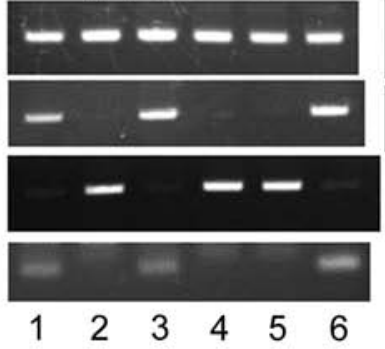

(III) miR200c

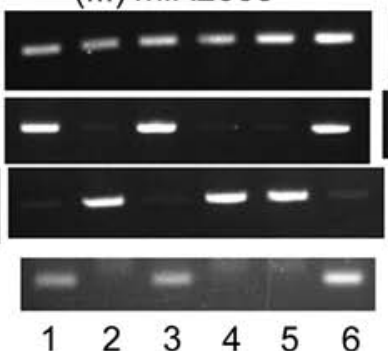

(IV) miR141

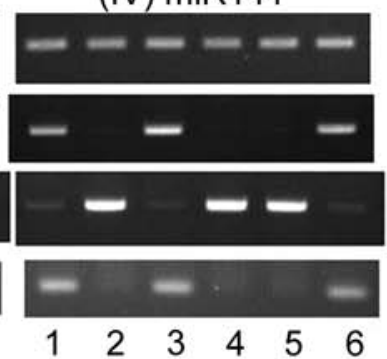

\section{B Protein expression}
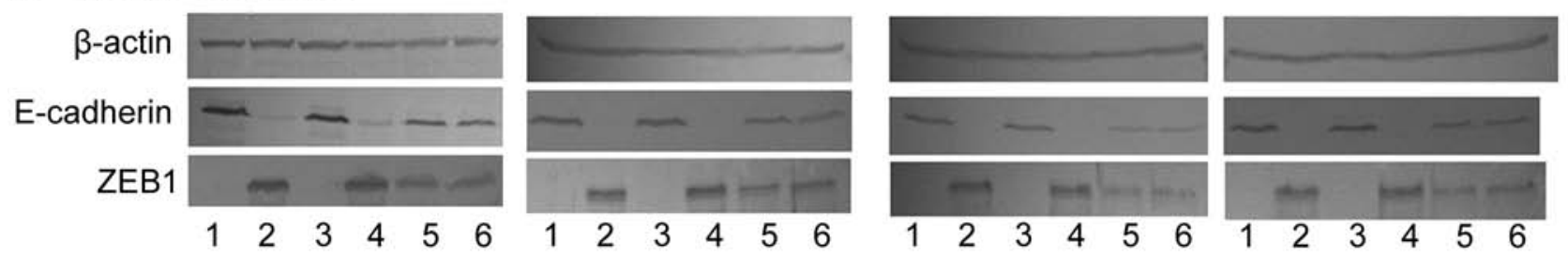

Figure 7. Effect of regulation of miR200 family expression on the expression of ZEB1 and CDH1 (E-cadherin) mRNA (A) and protein (B) in Ishikawa and Ish/EXM cells by transfection with the anti- and pre-miR200 family, respectively. Lane 1, Ishikawa cells; lane 2, Ish/EXM cells; lane 3, non-coding miR-transfected Ishikawa cells; lane 4, non-coding miR-transfected Ish/EXM cells; lane 5, anti-miR200 family (miR-200a, miR-200b, miR-200c and miR141)-transfected Ishikawa cells; lane 6, pre-miR200 family (miR-200a, miR-200b, miR-200c and miR-141)-transfected Ish/EXM cells.

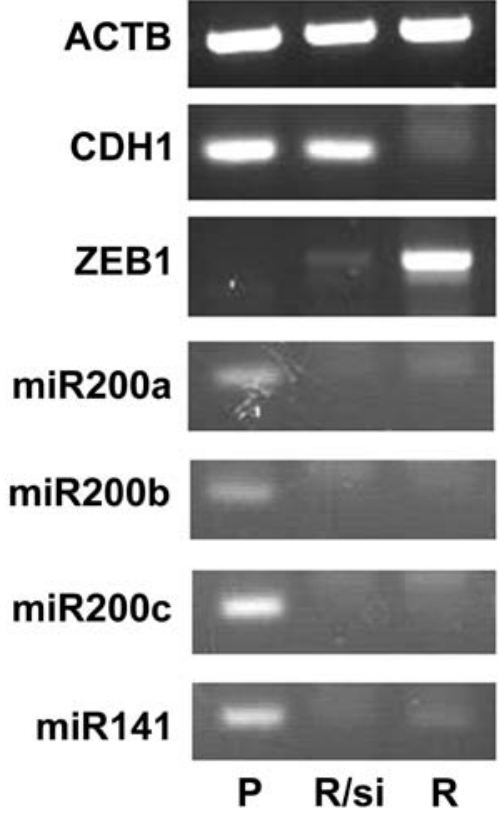

Figure 8. Effect of ZEB1 knockdown by siRNA on miR-200 family expression. $\mathrm{P}$, Ishikawa cells; R, Ish/EXM cells; R/si, Ish/EXM treated with siRNA for ZEB1. CDH1 and ZEB1 mRNA were determined by RT-PCR. The miR-200 family was measured using the QuantiMir kit.

This result demonstrated that E-cadherin was re-expressed in Ish/EXM cells in which ZEB1 was knocked down by treatment with siRNA but not by any other transcriptional suppressor factor (Figs. 4 and 8). ZEB2 also suppressed expression of E-cadherin in Ish/EXM cells, but the suppression was weaker in these cells (Fig. 4), possibly because E-cadherin was partly re-expressed in Ish/EXM cells in which ZEB2 had been knocked down by treatment with siRNA. Several studies have demonstrated that transcriptional suppression factors caused suppression of E-cadherin in various cells (32-37).

Since acquirement of EXM-resistance led to the disappearance of both E-cadherin mRNA (CDH1) and its protein in Ish/EXM cells, we studied whether the sensitivity of EXM decreased with CDH1-supressed Ishikawa cell by transfection of siRNA for CDH1. Conversely, we studied whether the sensitivity of EXM rose with Ish/EXM cell by transfection of siRNA for ZEB1. Sensitivity to EXM against CDH1-supressed Ishikawa cells showed 2-fold resistance compared to that against Ishikawa cells, and sensitivity to EXM against ZEB1supressed Ish/EXM cells showed 1.3-fold higher susceptibility compared to that against Ish/EXM cells (Fig. 5). Accordingly, the disappearance of E-cadherin partially participated in acquirement of EXM-resistance. Recently, we found that several drug-resistant factors, the cytochrome P450 family and ALDH family were highly expressed in Ish/EXM cells (data not shown). These factors may participate in EXM-resistance.

Since several miRNAs have been found to control EMT, such as miR-9, miR-10a, miR-10b, miR-21, miR-23a, miR-23b, miR-27a, miR-27b, miR-34a, miR-141, miR-150, miR-192, miR-200a, miR-200b, miR-200c, miR-205, miR-206, miR-215, miR-217, miR-221, miR-298, miR-374b, miR-382, miR-429, miR-508-3p and miR-539 in several cell types (48-64), we conducted quantitative tests to compare with the expression of these miRNAs in Ishikawa and Ish/EXM cells. As shown in Fig. 5, the miR200 family (miR-200a, miR-200b, miR-200c and miR-141) was suppressed in Ish/EXM cells.

In initial studies, an inverse correlation between the miR-200 family and ZEB1 was established in Ishikawa and Ish/EXM cells (Fig. 8). Suppression of ZEB1 by the miR-200 family resulted in enhanced expression of the key epithelial marker, E-cadherin and acquisition of an epithelial phenotype (Fig. 7). During the induction of EMT in Ish/EXM cells with 
acquirement of EXM-resistance, the miR-200 family and E-cadherin were repressed in parallel with an increase in ZEB1 expression. The ability to induce EMT was dependent upon suppression of the miR-200 family and induction of ZEB1 expression. Conversely, a mesenchymal-epithelial transition (MET) could be induced by expression of the miR-200 family in cells that were originally mesenchymal in nature (Fig. 8). These results confirm that the miR-200 family represses ZEB1 expression and consequently inhibits the progression of EMT by establishing and maintaining an epithelial phenotype. The suppression of ZEB1 expression by the miRNA-200 family is direct, and occurs as a result of the miRNA binding to the eight and the nine sites in the 30UTRs of ZEB1 (and ZEB2) mRNA $(65,73)$.

An additional level of miR200-ZEB1/ZEB2 protein regulation was identified in breast and colon cancer cell lines in which ZEB1 was constitutively downregulated by shRNA (39). Cells underwent MET, with corresponding upregulation of the miR-200 family, most notably the miR-141 and miR-200c transcripts. The miR-141 and miR-200c promoter contains multiple highly conserved E-boxes which are occupied by ZEB1 in mesenchymal cells leading to the transcriptional suppression. This finding was complemented by data showing that ZEB1-depleted cells retained the epithelial phenotype upon miR-200 inhibition. It was reported that a double-negative feedback loop controls ZEB1-SIP1 (ZEB2) and miR-200 family expression that regulates cellular phenotype and has direct relevance to the role of these factors in tumor progression (64,74-76). Data suggest that the majority, if not all, epithelial cells express high levels of the miR-200 family, which directly repress ZEB1 and ZEB2 and so enable the expression of E-cadherin. However, if an extracellular signal stimulates the expression of ZEB1, the miR-200 family is suppressed, thereby allowing EMT to proceed.

Moreover, investigating the effect of transfection with the anti- and pre-miR-200 family on both transcriptional suppression factor and E-cadherin expression in Ishikawa and Ish/EXM cells, respectively, led to an increase in expression of the miR-200 family in Ish/EXM cells by transfection with pre-miR-200 and suppression of ZEB1 and re-expression of E-cadherin (Fig. 7). By contrast, suppression of the miR-200 family in Ishikawa cells by transfection with anti-miR-200 family showed both expression of ZEB1 and suppression of E-cadherin (Fig. 7). Since suppression of ZEB1 in Ish/EXM cells by treatment with its siRNA did not restore miR-200 family expression, the miR-200 family was placed upstream of ZEB1 to regulate the expression (Fig. 8). It was suggested that this regulatory loop did not control ZEB1 and the miR-200 family in Ishikawa and Ish/EXM cells.

As we recently found that several drug-resistant factors, the cytochrome P450 family and ALDH family, and the ERK signal-regulating factors were highly expressed in Ish/EXM cells, further study will attempt to confirm the relationship between proteasome inhibitor resistance and EMT induction.

\section{Acknowledgements}

This study was partly supported by The Jikei University Research Fund.

\section{References}

1. Varshavsky A: The ubiquitin system. Trends Biochem Sci 22: 383-387, 1997.

2. Ciechanover A: The ubiquitin-proteasome pathway: On protein death and cell life. EMBO J 17: 7151-7160, 1998.

3. Hershko A and Ciechanover A: The ubiquitin system. Annu Rev Biochem 67: 425-479, 1998.

4. Voges D, Zwickl P and Baumeister W: The 26S proteasome: A molecular machine designed for controlled proteolysis. Annu Rev Biochem 68: 1015-1068, 1999.

5. Hershko A, Ciechanover A and Varshavsky A: Basic Medical Research Award. The ubiquitin system. Nat Med 6: 1073-1081, 2000.

6. Ciechanover A and Schwartz AL: Ubiquitin-mediated degradation of cellular proteins in health and disease. Hepatology 35 : 3-6, 2002.

7. Naujokat $\mathrm{C}$ and Hoffmann S: Role and function of the $26 \mathrm{~S}$ proteasome in proliferation and apoptosis. Lab Invest 82: 965-980, 2002.

8. Lee DH and Goldberg AL: Proteasome inhibitors: Valuable new tools for cell biologists. Trends Cell Biol 8: 397-403, 1998.

9. Adams J, Palombella VJ, Sausville EA, Johnson J, Destree A, Lazarus DD, Maas J, Pien CS, Prakash S and Elliott PJ: Proteasome inhibitors: A novel class of potent and effective antitumor agents. Cancer Res 59: 2615-2622, 1999.

10. Meng L, Mohan R, Kwok BH, Elofsson M, Sin N and Crews CM: Epoxomicin, a potent and selective proteasome inhibitor, exhibits in vivo antiinflammatory activity. Proc Natl Acad Sci USA 96: 10403-10408, 1999.

11. Hideshima T, Richardson P, Chauhan D, Palombella VJ, Elliott PJ, Adams J and Anderson KC: The proteasome inhibitor PS-341 inhibits growth, induces apoptosis, and overcomes drug resistance in human multiple myeloma cells. Cancer Res 61: 3071-3076, 2001.

12. Shah SA, Potter MW and Callery MP: Ubiquitin proteasome inhibition and cancer therapy. Surgery 131: 595-600, 2002.

13. Adams J: Preclinical and clinical evaluation of proteasome inhibitor PS-341 for the treatment of cancer. Curr Opin Chem Biol 6: 493-500, 2002.

14. Adams J: Proteasome inhibitors as new anticancer drugs. Curr Opin Oncol 14: 628-634, 2002.

15. Almond JB and Cohen GM: The proteasome: A novel target for cancer chemotherapy. Leukemia 16: 433-443, 2002.

16. Garber K: On the eve of protein destruction: Ubiquitin research begins to pay off. J Natl Cancer Inst 94: 550-552, 2002.

17. Hernandez AA and Roush WR: Recent advances in the synthesis, design and selection of cysteine protease inhibitors. Curr Opin Chem Biol 6: 459-465, 2002.

18. Ling YH, Liebes L, Ng B, Buckley M, Elliott PJ, Adams J, Jiang JD, Muggia FM and Perez-Soler R: PS-341, a novel proteasome inhibitor, induces $\mathrm{Bcl}-2$ phosphorylation and cleavage in association with G2-M phase arrest and apoptosis. Mol Cancer Ther 1: 841-849, 2002.

19. Sakamoto KM: Ubiquitin-dependent proteolysis: Its role in human diseases and the design of therapeutic strategies. Mol Genet Metab 77: 44-56, 2002.

20. Smith DM, Wang Z, Kazi A, Li LH, Chan TH and Dou QP: Synthetic analogs of green tea polyphenols as proteasome inhibitors. Mol Med 8: 382-392, 2002.

21. Yu R, Ren SG and Melmed S: Proteasome inhibitors induce apoptosis in growth hormone- and prolactin-secreting rat pituitary tumor cells. J Endocrinol 174: 379-386, 2002.

22. LeBlanc R, Catley LP, Hideshima T, et al: Proteasome inhibitor PS-341 inhibits human myeloma cell growth in vivo and prolongs survival in a murine model. Cancer Res 62: 4996-5000, 2002.

23. Orlowski RZ, Stinchcombe TE, Mitchell BS, et al: Phase I trial of the proteasome inhibitor PS-341 in patients with refractory hematologic malignancies. J Clin Oncol 20: 4420-4427, 2002.

24. Ohkawa K, Asakura T, Aoki K, Shibata S, Minami J, Fujiwara C, Sai T, Marushima $\mathrm{H}$ and Kuzuu $\mathrm{H}$ : Establishment and some characteristics of epoxomicin (a proteasome inhibitor) resistant variants of the human squamous cell carcinoma cell line, A431. Int J Oncol 24: 425-433, 2004.

25. Duband JL, Monier F, Delannet M and Newgreen D: Epitheliummesenchyme transition during neural crest development. Acta Anat (Basel) 154: 63-78, 1995.

26. Viebahn C: Epithelio-mesenchymal transformation during formation of the mesoderm in the mammalian embryo. Acta Anat (Basel) 154: 79-97, 1995. 
27. Birchmeier W and Behrens J: Cadherin expression in carcinomas: Role in the formation of cell junctions and the prevention of invasiveness. Biochim Biophys Acta 1198: 11-26, 1994.

28. Bussemakers MJG, van Bokhoven A, Völler M, Smit FP and Schalken JA: The genes for the calcium-dependent cell adhesion molecules $\mathrm{P}$ - and E-cadherin are tandemly arranged in the human genome. Biochem Biophys Res Commun 203: 1291-1294, 1994.

29. Berx G, Cleton-Jansen AM, Nollet F, de Leeuw WJ, van de Vijver M, Cornelisse C and van Roy F: E-cadherin is a tumour/invasion suppressor gene mutated in human lobular breast cancers. EMBO J 14: 6107-6115, 1995.

30. Takeichi M: Cadherins in cancer: Implications for invasion and metastasis. Curr Opin Cell Biol 5: 806-811, 1993.

31. Christofori $\mathrm{G}$ and Semb $\mathrm{H}$ : The role of the cell-adhesion molecule E-cadherin as a tumour-suppressor gene. Trends Biochem Sci 24: 73-76, 1999.

32. Batlle E, Sancho E, Francí C, Domínguez D, Monfar M, Baulida J and García De Herreros A: The transcription factor snail is a repressor of E-cadherin gene expression in epithelial tumour cells. Nat Cell Biol 2: 84-89, 2000.

33. Cano A, Pérez-Moreno MA, Rodrigo I, Locascio A, Blanco MJ, del Barrio MG, Portillo F and Nieto MA: The transcription factor snail controls epithelial-mesenchymal transitions by repressing E-cadherin expression. Nat Cell Biol 2: 76-83, 2000

34. Bolós V, Peinado H, Pérez-Moreno MA, Fraga MF, Esteller M and Cano A: The transcription factor Slug represses E-cadherin expression and induces epithelial to mesenchymal transitions: A comparison with Snail and E47 repressors. J Cell Sci 116 : 499-511, 2003

35. Comijn J, Berx G, Vermassen P, Verschueren K, van Grunsven L, Bruyneel E, Mareel M, Huylebroeck D and van Roy F: The twohanded $\mathrm{E}$ box binding zinc finger protein SIP1 downregulates E-cadherin and induces invasion. Mol Cell 7: 1267-1278, 2001.

36. Perez-Moreno MA, Locascio A, Rodrigo I, Dhondt G, Portillo F Nieto MA and Cano A: A new role for E12/E47 in the repression of E-cadherin expression and epithelial-mesenchymal transitions. J Biol Chem 276: 27424-27431, 2001.

37. Yang J, Mani SA, Donaher JL, Ramaswamy S, Itzykson RA, Come C, Savagner P, Gitelman I, Richardson A and Weinberg RA Twist, a master regulator of morphogenesis, plays an essential role in tumor metastasis. Cell 117: 927-939, 2004.

38. Berx G, Raspé E, Christofori G, Thiery JP and Sleeman JP: Pre-EMTing metastasis? Recapitulation of morphogenetic processes in cancer. Clin Exp Metastasis 24: 587-597, 2007.

39. Burk U, Schubert J, Wellner U, Schmalhofer O, Vincan E, Spaderna $\mathrm{S}$ and Brabletz T: A reciprocal repression between ZEB1 and members of the miR-200 family promotes EMT and invasion in cancer cells. EMBO Rep 9: 582-589, 2008.

40. Esquela-Kerscher A and Slack FJ: Oncomirs - microRNAs with a role in cancer. Nat Rev Cancer 6: 259-269, 2006.

41. Korpal M and Kang Y: The emerging role of miR-200 family of microRNAs in epithelial-mesenchymal transition and cancer metastasis. RNA Biol 5: 115-119, 2008.

42. Korpal M,Lee ES,Hu G and Kang Y: The miR-200 family inhibits epithelial-mesenchymal transition and cancer cell migration by direct targeting of E-cadherin transcriptional repressors ZEB1 and ZEB2. J Biol Chem 283: 14910-14914, 2008.

43. Park SM, Gaur AB, Lengyel E and Peter ME: The miR-200 family determines the epithelial phenotype of cancer cells by targeting the E-cadherin repressors ZEB1 and ZEB2. Genes Dev 22: 894-907, 2008.

44. Peter ME: Let-7 and miR-200 microRNAs: Guardians against pluripotency and cancer progression. Cell Cycle 8: 843-852, 2009.

45. Spaderna S, Brabletz T and Opitz OG: The miR-200 family: central player for gain and loss of the epithelial phenotype. Gastroenterology 136: 1835-1837, 2009.

46. Lee Y, Ahn C, Han J, et al: The nuclear RNase III Drosha initiates microRNA processing. Nature 425: 415-419, 2003.

47. Yi R, Qin Y, Macara IG and Cullen BR: Exportin-5 mediates the nuclear export of pre-microRNAs and short hairpin RNAs. Genes Dev 17: 3011-3016, 2003.

48. Hutvágner G, McLachlan J, Pasquinelli AE, Bálint E, Tuschl T and Zamore PD: A cellular function for the RNA-interference enzyme Dicer in the maturation of the let-7 small temporal RNA. Science 293: 834-838, 2001.

49. Wienholds E, Kloosterman WP, Miska E, Alvarez-Saavedra E, Berezikov E, de Bruijn E, Horvitz HR, Kauppinen S and Plasterk RH: MicroRNA expression in zebrafish embryonic development. Science 309: 310-311, 2005.
50. Yi R, O'Carroll D, Pasolli HA, Zhang Z, Dietrich FS, Tarakhovsky A and Fuchs E: Morphogenesis in skin is governed by discrete sets of differentially expressed microRNAs. Nat Genet 38: 356-362, 2006

51. Johnson SM, Grosshans H, Shingara J, Byrom M, Jarvis R, Cheng A, Labourier E, Reinert KL, Brown D and Slack FJ: RAS is regulated by the let-7 microRNA family. Cell 120: 635-647, 2005.

52. Huang Q, Gumireddy K, Schrier M, et al: The microRNAs miR-373 and miR-520c promote tumour invasion and metastasis. Nat Cell Biol 10: 202-210, 2008

53. Ma L, Teruya-Feldstein J and Weinberg RA: Tumour invasion and metastasis initiated by microRNA-10b in breast cancer. Nature 449: 682-688, 2007.

54. Tavazoie SF, Alarcón C, Oskarsson T, Padua D, Wang Q, Bos PD, Gerald WL and Massagué J: Endogenous human microRNAs that suppress breast cancer metastasis. Nature 451: 147-152, 2008

55. Zhu S, Wu H, Wu F, Nie D, Sheng S and Mo YY: MicroRNA-21 targets tumor suppressor genes in invasion and metastasis. Cell Res 18: 350-359, 2008

56. Asangani IA, Rasheed SA, Nikolova DA, Leupold JH, Colburn NH, Post S and Allgayer H: MicroRNA-21 (miR-21) post-transcriptionally downregulates tumor suppressor Pdcd4 and stimulates invasion, intravasation and metastasis in colorectal cancer. Oncogene 27: 2128-2136, 2008.

57. Akao Y, Nakagawa $Y$ and Naoe T: let-7 microRNA functions as a potential growth suppressor in human colon cancer cells. Biol Pharm Bull 29: 903-906, 2006.

58. Calin GA, Dumitru CD, Shimizu M, et al: Frequent deletions and down-regulation of micro-RNA genes miR15 and miR16 at 13 q14 in chronic lymphocytic leukemia. Proc Natl Acad Sci USA 99: 15524-15529, 2002.

59. Johnson CD, Esquela-Kerscher A, Stefani G, et al: The let-7 microRNA represses cell proliferation pathways in human cells. Cancer Res 67: 7713-7722, 2007.

60. Takamizawa J, Konishi H, Yanagisawa K, et al: Reduced expression of the let-7 microRNAs in human lung cancers in association with shortened postoperative survival. Cancer Res 64: 3753-3756, 2004

61. Yanaihara N, Caplen N, Bowman E, Seike M, Kumamoto K, Yi M, Stephens RM, Okamoto A, Yokota J and Tanaka T: Unique microRNA molecular profiles in lung cancer diagnosis and prognosis. Cancer Cell 9: 189-198, 2006.

62. He L, Thomson JM, Hemann MT, et al: A microRNA polycistron as a potential human oncogene. Nature 435: 828-833, 2005.

63. Voorhoeve PM, le Sage C, Schrier M, et al: A genetic screen implicates miRNA-372 and miRNA-373 as oncogenes in testicular germ cell tumors. Cell 124: 1169-1181, 2006

64. Bracken CP, Gregory PA, Kolesnikoff N, Bert AG, Wang J, Shannon MF and Goodall GJ: A double-negative feedback loop between ZEB1-SIP1 and the microRNA-200 family regulates epithelial-mesenchymal transition. Cancer Res 68: 7846-7854, 2008.

65. Gregory PA, Bert AG, Paterson EL, Barry SC, Tsykin A, Farshid G, Vadas MA, Khew-Goodall Y and Goodall GJ: The miR-200 family and miR-205 regulate epithelial to mesenchymal transition by targeting ZEB1 and SIP1. Nat Cell Biol 10: 593-601, 2008.

66. Spaderna S, Schmalhofer O, Hlubek F, Jung A, Kirchner T and Brabletz T: Epithelial-mesenchymal and mesenchymal-epithelial transitions during cancer progression. Verh Dtsch Ges Pathol 91: 21-28, 2007.

67. Cano A and Nieto MA: Non-coding RNAs take centre stage in epithelial-to-mesenchymal transition. Trends Cell Biol 18 357-359, 2008.

68. Gregory PA, Bracken CP, Bert AG and Goodall GJ: MicroRNAs as regulators of epithelial-mesenchymal transition. Cell Cycle 7: 3112-3118, 2008.

69. Savagner P: Leaving the neighborhood: Molecular mechanisms involved during epithelial-mesenchymal transition. BioEssays 23: 912-923, 2001.

70. Brabletz T, Jung A, Reu S, Porzner M, Hlubek F, KunzSchughart LA, Knuechel R and Kirchner T: Variable beta-catenin expression in colorectal cancers indicates tumor progression driven by the tumor environment. Proc Natl Acad Sci USA 98: 10356-10361, 2001.

71. Dvorak HF: Tumors: Wounds that do not heal. Similarities between tumor stroma generation and wound healing. N Engl J Med 315: 1650-1659, 1986. 
72. Fuchs IB, Lichtenegger W, Buehler H, Henrich W, Stein $\mathrm{H}$, Kleine-Tebbe A and Schaller G: The prognostic significance of epithelial-mesenchymal transition in breast cancer. Anticancer Res 22: 3415-3419, 2002.

73. Huang HN, Chen SY, Hwang SM, et al: miR-200c and GATA binding protein 4 regulate human embryonic stem cell renewal and differentiation. Stem Cell Res (Amst) 12: 338-353, 2014.

74. Moes M, Le Béchec A, Crespo I, Laurini C, Halavatyi A, Vetter G, Del Sol A and Friederich E: A novel network integrating a miRNA-203/SNAI1 feedback loop which regulates epithelial to mesenchymal transition. PLoS One 7: e35440, 2012.
75. Brabletz S and Brabletz T: The ZEB/miR-200 feedback loop - a motor of cellular plasticity in development and cancer? EMBO Rep 11: 670-677, 2010.

76. Hill L, Browne G and Tulchinsky E: ZEB/miR-200 feedback loop: At the crossroads of signal transduction in cancer. Int $\mathrm{J}$ Cancer 132: 745-754, 2013. 